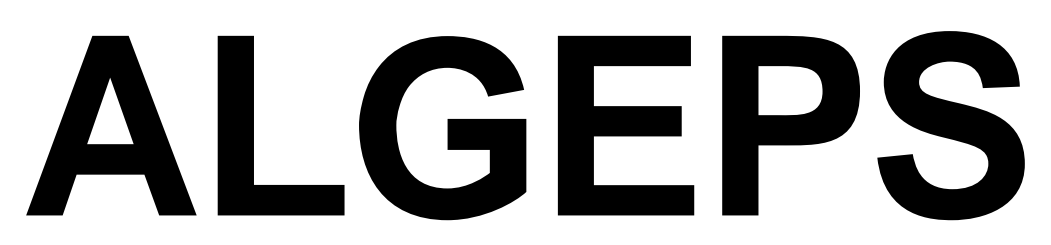

REVISTA DE GEOLOGIA, SÈRIE B no 591 - Maig del 2012

RECORRIDO DESDE L'AINSA A TIERRANTONA, Y A SALINAS DE TRILLO, A TRAVÉS DEL PATRIMONIO GEOLÓGICO Y MINERO DE LA COMARCA DEL SOBRARBE

Josep M. Mata-Perelló

Aquest recorregut va ésser experimentat amb docents el dia 15 DE JUNY DEL 2010 


\section{RECORRIDO DESDE L'AINSA A TIERRANTONA Y A SALINAS DE TRILLO, A TRAVÉS DEL PATRIMONIO GEOLÓGICO Y MINERO DE LA COMARCA DEL SOBRARBE}

\section{ADVERTENCIAS PREVIAS}

Como en otros recorridos de RECONOCIMIENTO GEOLÓGICO (o de RECONOCIMIENTO GEOLÓGICO Y MINERO), el recorrido se compondrá de diversas PARADAS.

Por otra parte, habrá que tener en cuenta, en todo momento, (especialmente antes de empezar los recorridos de los diferentes tramos), el estado de los caminos y carreteras, por donde transitará el recorrido. Como es el caso del camino de acceso a las Salinas de Trillo, entre otros lugares.

Finalmente, como ya hacemos en otros recorridos similares, queremos decir que hace falta tener un cuidado muy especial en el respeto a la naturaleza, a lo largo de todo el recorrido del itinerario, y también fuera de él.

\section{BREVE INTRODUCCIÓN GEOLÓGICA}

Todo el recorrido de este itinerario, se desarrollará por distintas zonas ocupadas por el Sistema Pirenaico (o simplemente por los Pirineos). Concretamente, en todo el recorrido se circulará por el denominado Surpirineo Central.

Así, el recorrido se iniciará en las cercanías de l’Ainsa, dentro del denominado Surpirineo Central, por los denominados Pirineos Meridionales (también a menudo conocidos como Prepirineo Meridional).

Así, se irá circulando desde l'Ainsa hasta Tierrantona y Palo, pasando del valle del Cinca a la Fueva.

\section{BREVE INTRODUCCIÓN GEOGRÁFICA}

El recorrido del presente itinerario se efectuará exclusivamente por una comarca aragonesa, por la del Sobrarbe. Así el recorrido se iniciará en la población de l'Ainsa, para ir hacía Tierrantona, y posteriormente hacía Salinas de Trillo, recorriendo la mayor parte del municipio de la Fueva. 
Por otro lado, la totalidad del recorrido transitará por la cuenca del río Cinca, aunque lo hará en buena parte la cuenca del Barranco de la Usia que drena parte de la Fueva hacía el Cinca.

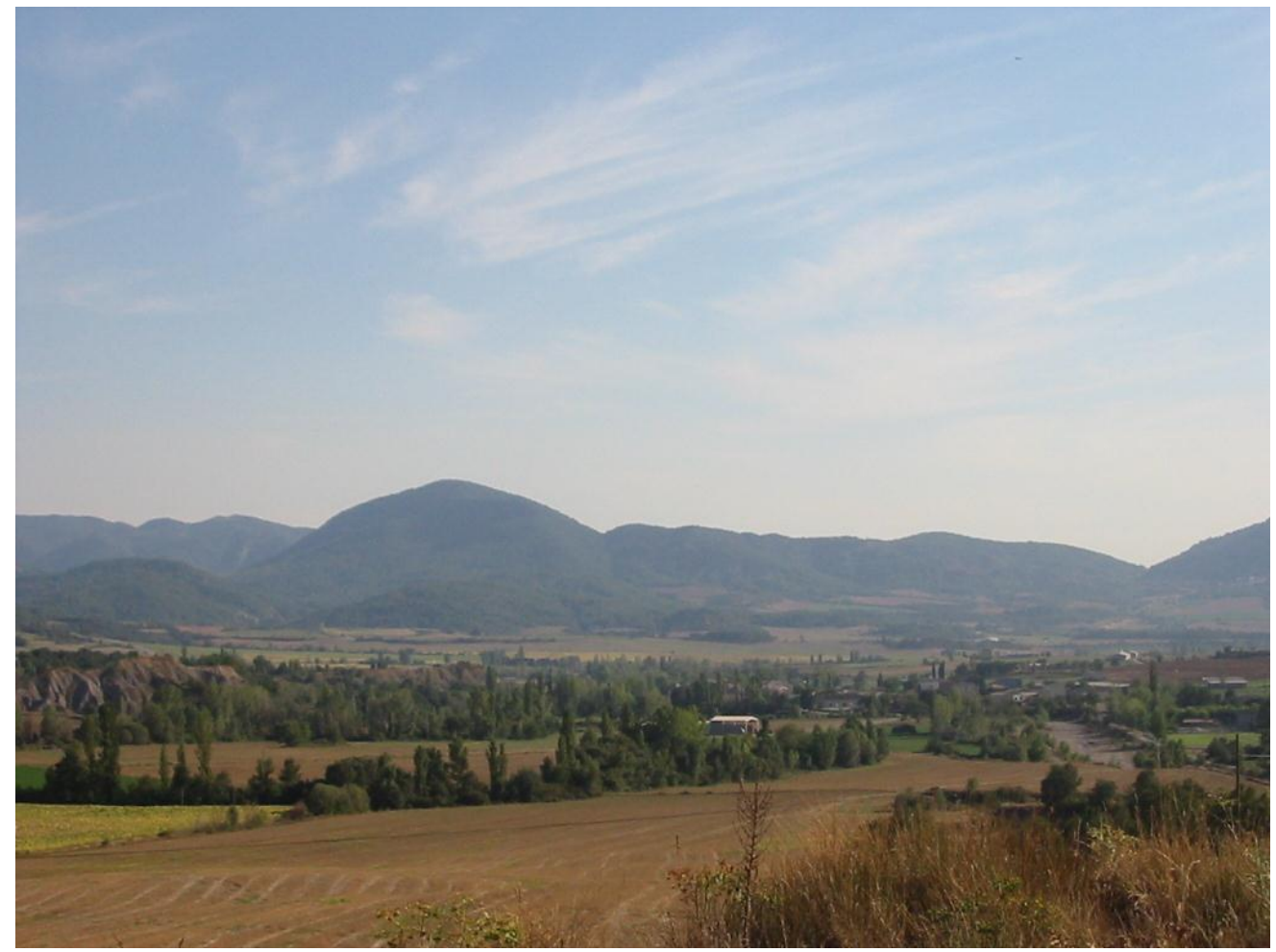

Un aspecto de la Fueva

\section{OBJETIVOS GENERALES DE ESTE ITINERARIO}

En este itinerario, los objetivos generales que se han de conseguir, se pueden concretar en los siguientes aspectos:

1.- Estudio y reconocimiento de los materiales mesozoicos y cenozoicos situados en el Surpirineo Central. Estos materiales los iremos encontrando a lo largo de todo el recorrido del itinerario.

2.- Estudio y reconocimiento de las estructuras del Surpirineo Central, a lo largo de todo el recorrido del itinerario.

3.- Visión de algunas de las antiguas explotaciones mineras encontradas a lo largo del recorrido del itinerario.

4.- Visión de los diferentes lugares directamente relacionados con el Patrimonio Geológico que iremos encontrando a lo largo del recorrido de este itinerario.

5.- Visión de los diferentes lugares directamente relacionados con el Patrimonio Minero que veremos a lo largo del recorrido de este itinerario. Dentro de este, cabe mencionar el relacionado con las Salinas de Trillo. 


\section{ANTECEDENTES BIBLIOGRÁFICOS}

En relación con este itinerario, no conocemos ningún antecedente, de otro autor relativo a otro itinerario que discurra por este lugar. Tampoco nosotros hemos escrito ningún itinerario que discurra por estos lugares. Así pues, en este sentido el que ahora presentamos va a ser una primicia en todos los aspectos.

Por otra parte, haremos mención de algunos trabajos, de carácter geológico generalista, que corresponden a los trabajos del IGME (1972, 1974 y 1975), relativos al Mapa Geológico de España (a Escala 1.200.000), al Mapa Metalogenético de España y al Mapa de Rocas Industriales de España.

Con respecto a las mineralizaciones que iremos encontrando, mencionaremos los trabajos de: CALVO et altri (1988); MAESTRE (1845); así como nuestros trabajos: MATA-PERELLÓ (1987 y 1992).

También mencionaremos el trabajo de PRAMES (2005) dedicado a la comarca del Sobrarbe. Así como el del GOBIERNO DE ARAGÓN (2001), dedicado a los Puntos de Interés Geológico de Aragón.

Finalmente, diremos que todos estos trabajos (así como otros que ahora no hemos aludido), figurarán mencionados, por orden alfabético, en el apartado dedicado a las REFERENCIAS BIBLIOGRÁFICAS.

\section{RECORRIDO DEL ITINERARIO}

Este recorrido se iniciará en las inmediaciones de la población de l'Ainsa, desde donde se dirigirá hacía el levante, por la carretera N-260, la que conduce a Campo. Por ella nos acercaremos a Arro. Mas adelante encontraremos el ramal de Tierrantona, yendo hacía Rañín, por donde realizaremos una parada. Después iremos a Solipueyo (donde haremos otra parada).

Desde ahí nos acercaremos a Tierrantona, para efectuar una nueva parada. Seguidamente pasaremos por Morillo de Monclús. Desde ahí, nos convendrá ir hacía Formigales, para acercarnos luego a Salinas de Trillo, en donde haremos una nueva parada en las salinas.

\section{DESCRIPCIÓN DEL ITINERARIO}

Como de costumbre, haremos una serio de PARADAS (o ESTACIONES), en donde se realizaran diversas explicaciones en torno a las características del lugar en donde se halla la PARADA.

Por otra parte, en ellas haremos mención del término municipal dónde se encuentran, así como del número del "Mapa Topográfico Nacional (a escala 1:50.000, 
que indicaremos entre paréntesis. Así, ahora (en este recorrido) utilizaremos solamente las hojas: 211 (o de Boltaña), 212 (o de Campo) y 250 (o de Graus).

Así, la relación ordenada de las paradas que constituyen el recorrido de este itinerario, es la siguiente:

PARADA 1. TEJAR DE RAÑÍN, (Rañín, término municipal de la Fueva, comarca del Sobrarbe). (Hoja 212).

El recorrido del presente itinerario, cabe iniciarlo en la población de 1'Ainsa (una de las dos capitales comarcales). Desde ahí, nos convendrá tomar la carretera N-260 hacía el Este, hacía Campo. Por ella pasaremos por Arro. Más adelante, al encontrar (por la izquierda) el ramal de Tierrantona, nos convendrá tomarlo, pasando cerca de la Sierra. Luego, por la izquierda encontraremos el ramal de Alueza y del Humo de Rañin, pasando por estos dos pueblos. Continuando hacía Rañín, antes de llegar a el efectuaremos la primera parada. Así, desde el inicio hasta aquí, habremos recorrido unos $22^{\prime} 5 \mathrm{Km}$, estando ahora a algo más de 0’5 Km del pueblo de Rañín.

En este recorrido habremos ido encontrando los materiales mesozoicos y cenozoicos que forman parte del Pirineo Meridional, por donde se desarrollará la totalidad del recorrido. Dentro de este conjunto de afloramientos, cabe mencionar los niveles de calcolutitas gris - azuladas que encontraremos entre l’Ainsa y Arro.

En este lugar hay los restos de un tejar (el tejar de Rañin). En él se aprovechaban unas calcolutitas muy arcillosas de los alrededores. El tejar se halla en un avanzado estado de ruina, formando parte del Patrimonio Minero del Sobrarbe.

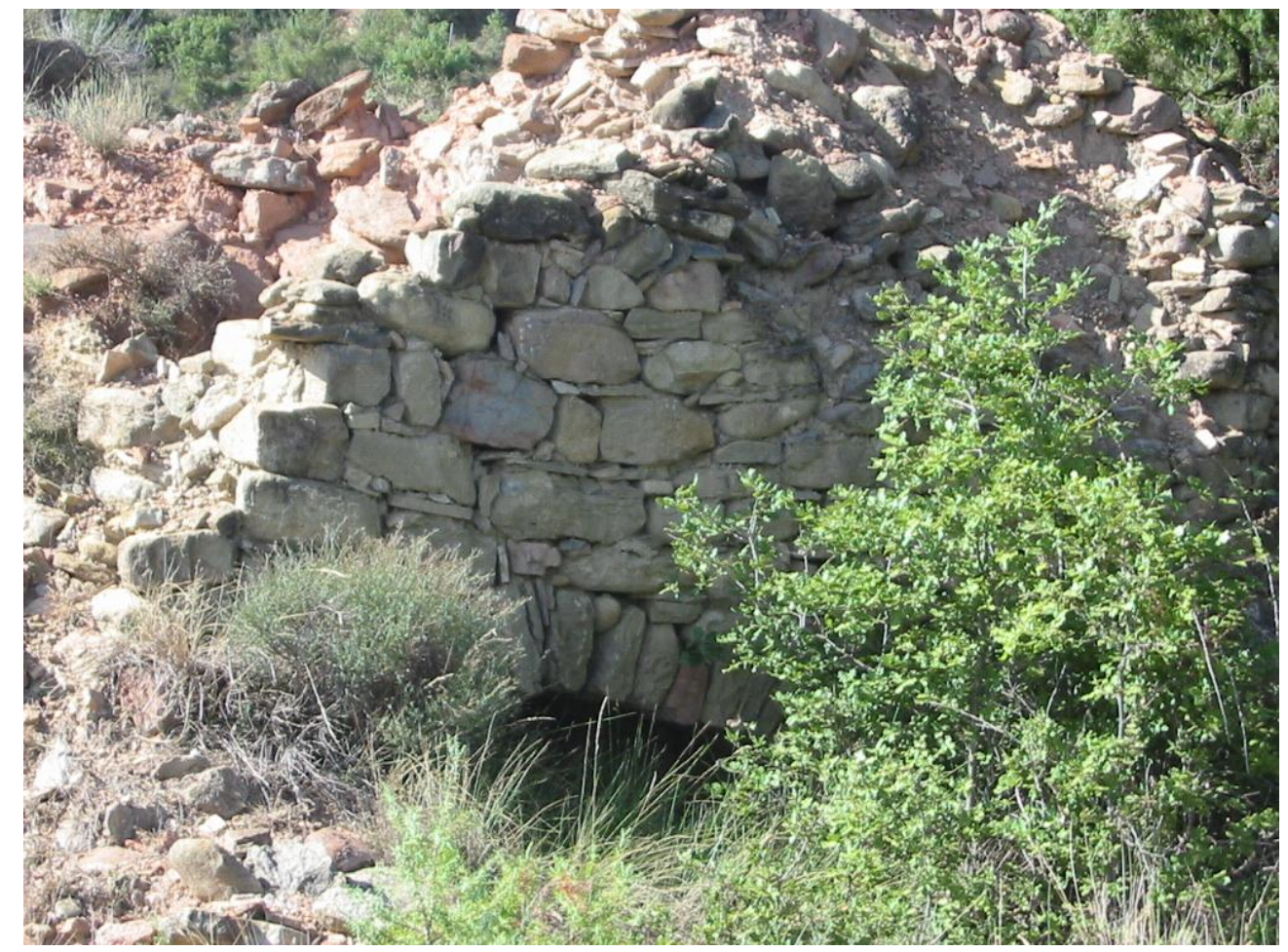

Boca del horno del Tejar de Rañin 
PARADA 2. TEJAR DE SOLIPUEYO, (Solipueyo, término municipal de la Fueva, comarca del Sobrarbe). (Hoja 212).

Después de realizar la parada anterior, cabe llegar hasta la cercana población de Rañín. Luego, desde ahí, nos interesará seguir hacía Solipueyo, con la intención de ir luego hacía el lugar en donde se halla el Tejar de Solipueyo. Ahí (a menos de $1 \mathrm{Km}$ al Oeste del pueblo) haremos una nueva parada. Así, desde la parada anterior, habremos recorrido menos de $3 \mathrm{Km}$, para llegar hasta este lugar.

En este recorrido, habremos encontrado afloramientos de los materiales ya citados en el recorrido anterior. Por otra parte, en este lugar encontraremos un tejar (el mencionado Tejar de Solipueyo) en un estado bastante ruinoso de conservación. Aun así, forma parte del Patrimonio Minero del Sobrarbe.

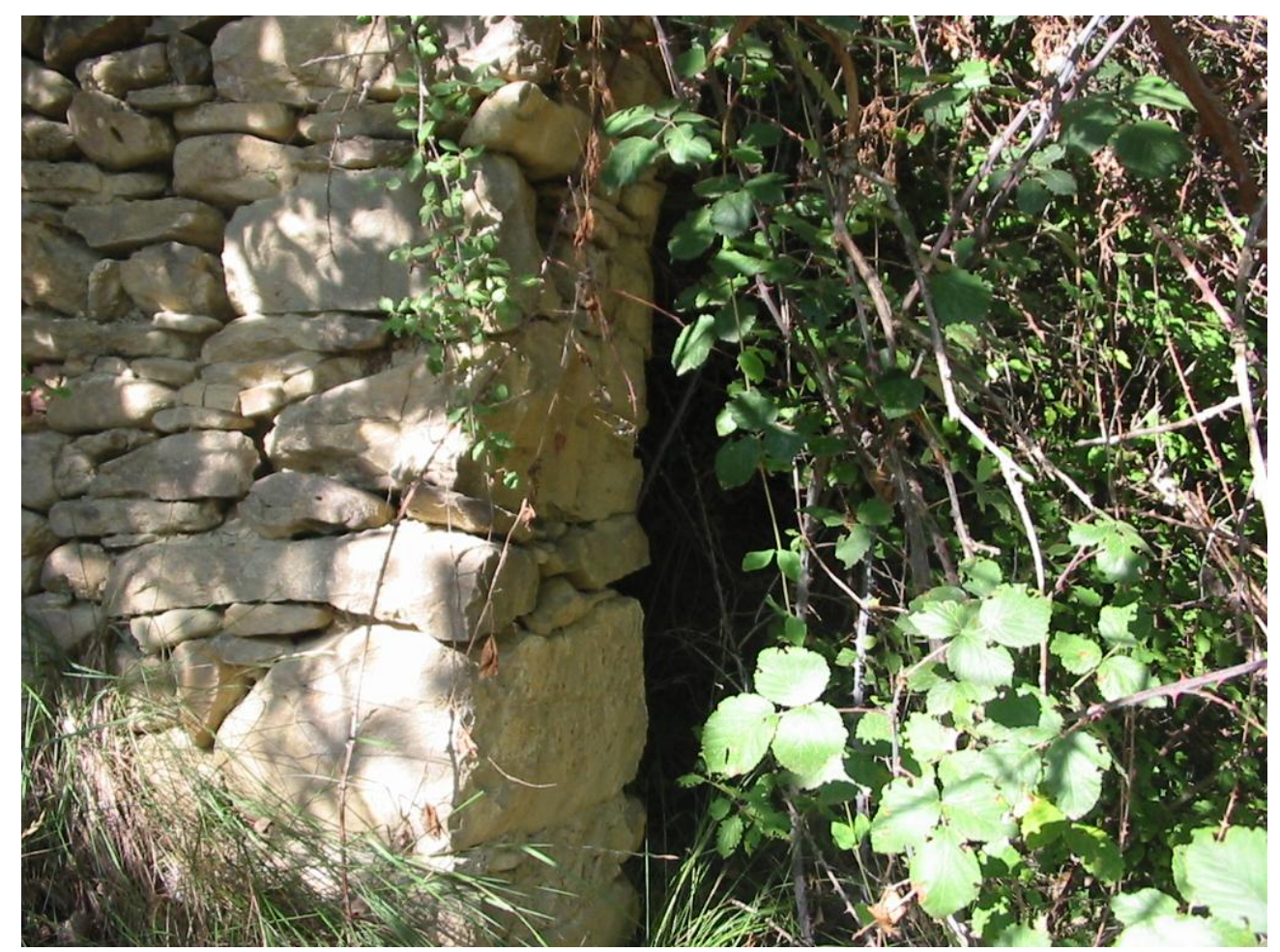

Restos de la pared del horno. Tejar de Solipueyo

PARADA 3. TEJAR DE TIERRANTONA, (Tierrantona, término municipal de la Fueva, comarca del Sobrarbe). (Hoja 212).

Desde la parada anterior, es necesario retornar a Solipueyo, con la intención de continuar por la carretera que conduce hacía Tierrantona, la capital del municipio de la Fueva. Desde ahí, nos convendrá tomar el camino - carretero que conduce al Pamporciello. A unos $2 \mathrm{Km}$ de Tierrantona encontraremos los restos de un antiguo tejar. Ahí efectuaremos una nueva parada, a unos $5 \mathrm{Km}$ de la anterior.

En este recorrido, al igual que en los anteriores, habremos vuelto a encontrar afloramientos de los materiales mesozoicos y cenozoicos. Estos materiales forman parte 
del Pirineo Meridional, en donde nos encontramos ahora, por donde estamos efectuando la totalidad del recorrido de este itinerario.

En este lugar hay los restos (muy transformadlos por la construcción de una casa) del Tejar de Tierrantona. En este tejar se utilizaban unos materiales calcolutíticos, muy arcillosos, extraídos de las cercanías.

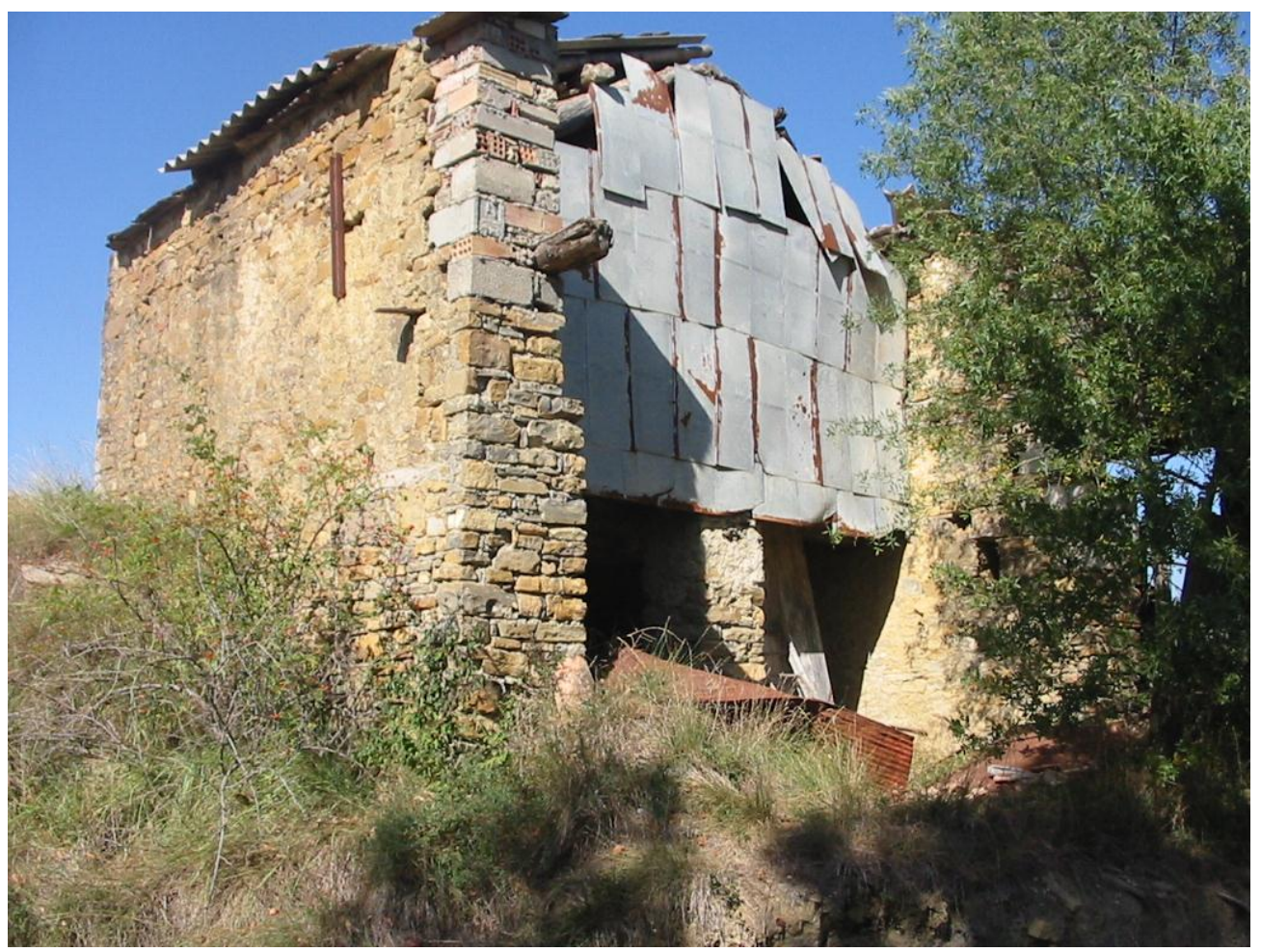

Restos del Tejar de la Sierra, de Tierrantona

PARADA 4. SALINAS DE TRILLO, (Salinas de Trillo, término municipal de la Fueva, comarca del Sobrarbe). (Hoja 250).

Tras realizar la parada anterior, conviene retornar a las inmediaciones de Tierrantona. Luego desde ahí nos convendrá ir hacía el cercano pueblo de Morillo de Monclús. Desde ahí, nos convendrá tomar la carretera de Troncedo, así pasaremos Formigales. Posteriormente, continuando hacía Troncedo, a $1 \mathrm{~km}$ antes de llegar a ese pueblo, encontraremos el ramal (por la derecha) que conduce a Trillo. Así, antes llegaremos a Salinas de Trillo, en donde haremos una nueva parada en las salinas. Para ir hacía ellas, tendremos que tomar un camino (a menos de 100 metros del pueblo). Este camino descendente, nos llevará en $1 \mathrm{Km}$ a las salinas. Ahí haremos una nueva parada, la última de este itinerario, a unos $14 \mathrm{Km}$ de la anterior.

Este recorrido lo habremos efectuado entre los afloramientos de los materiales citados anteriormente. Así en las salinas afloran unas calcolutitas gris - azuladas, Cerca de ellas, por debajo, hay un afloramiento de los materiales triásicos del Keuper, con niveles de arcillas y yesos. Entre estos materiales había una fuente de agua salada. Ésta, se había situado al alumbrar las aguas saladas, procedentes de la disolución de la halita 
contenida entre los yesos, por donde habían circulado las aguas subterráneas. Posteriormente, con un elevador, esta agua llegaba a las salinas y se esparcía por las eras. Ahí, el agua se evaporaba, obteniéndose la sal común, la HALITA.

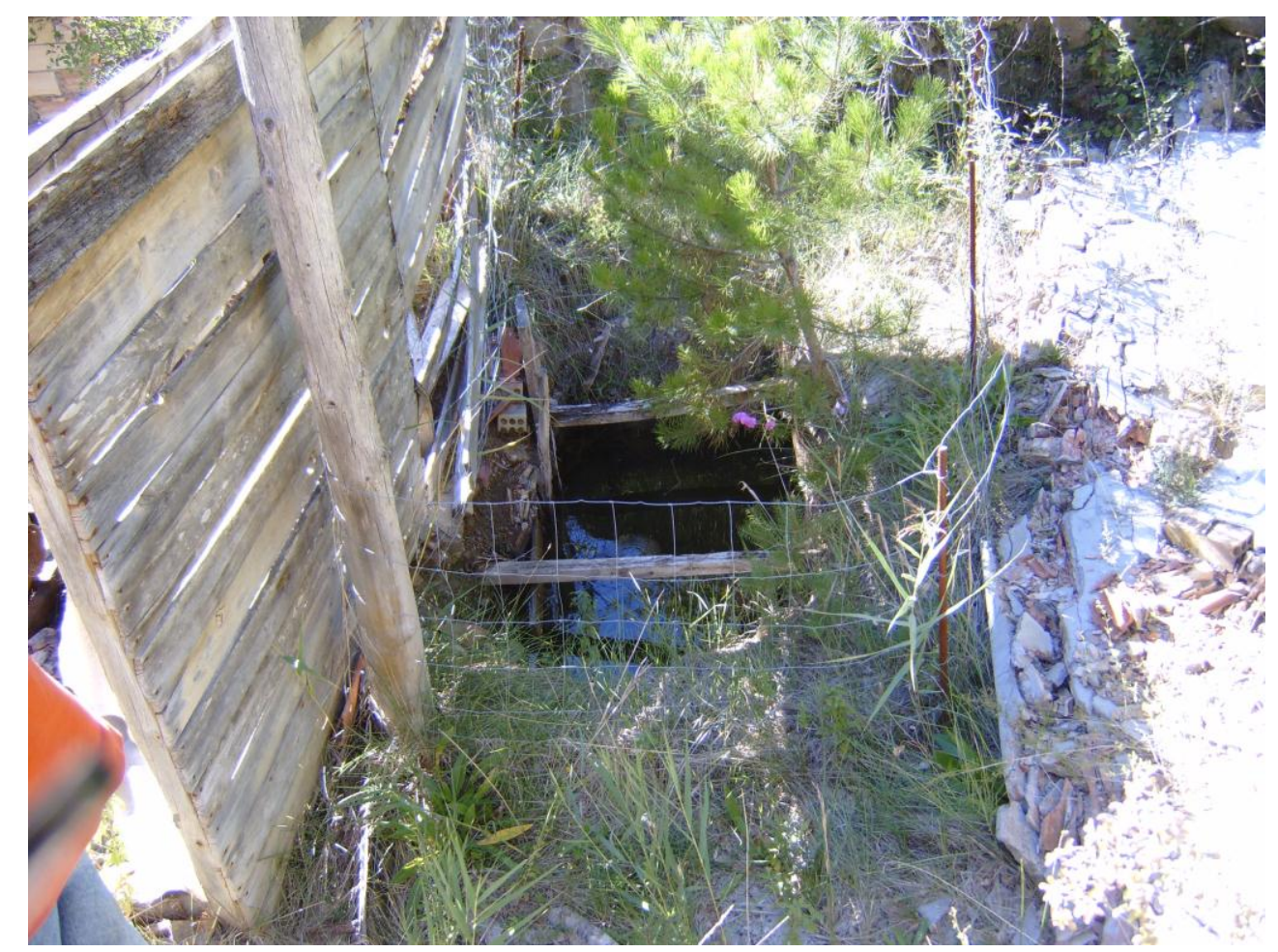

Lugar en donde se halla la fuente

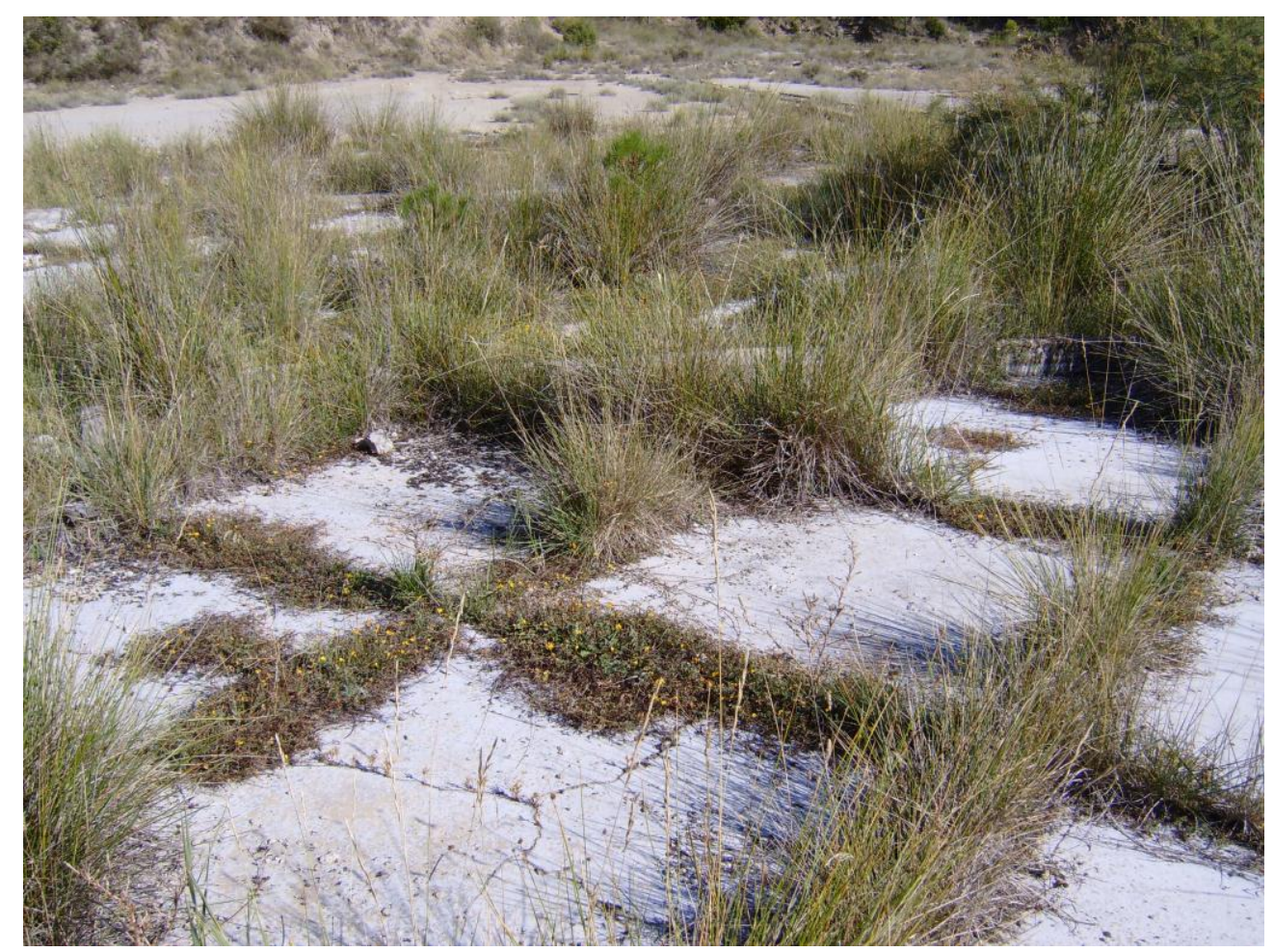

Estado actual de las eras 
Con todo ello se ha generado un importante Patrimonio Minero, por el que es necesario velar, conservándolo e impidiendo su destrucción, como ahora está sucediendo con parte de él, como con la Casa de las Salinas

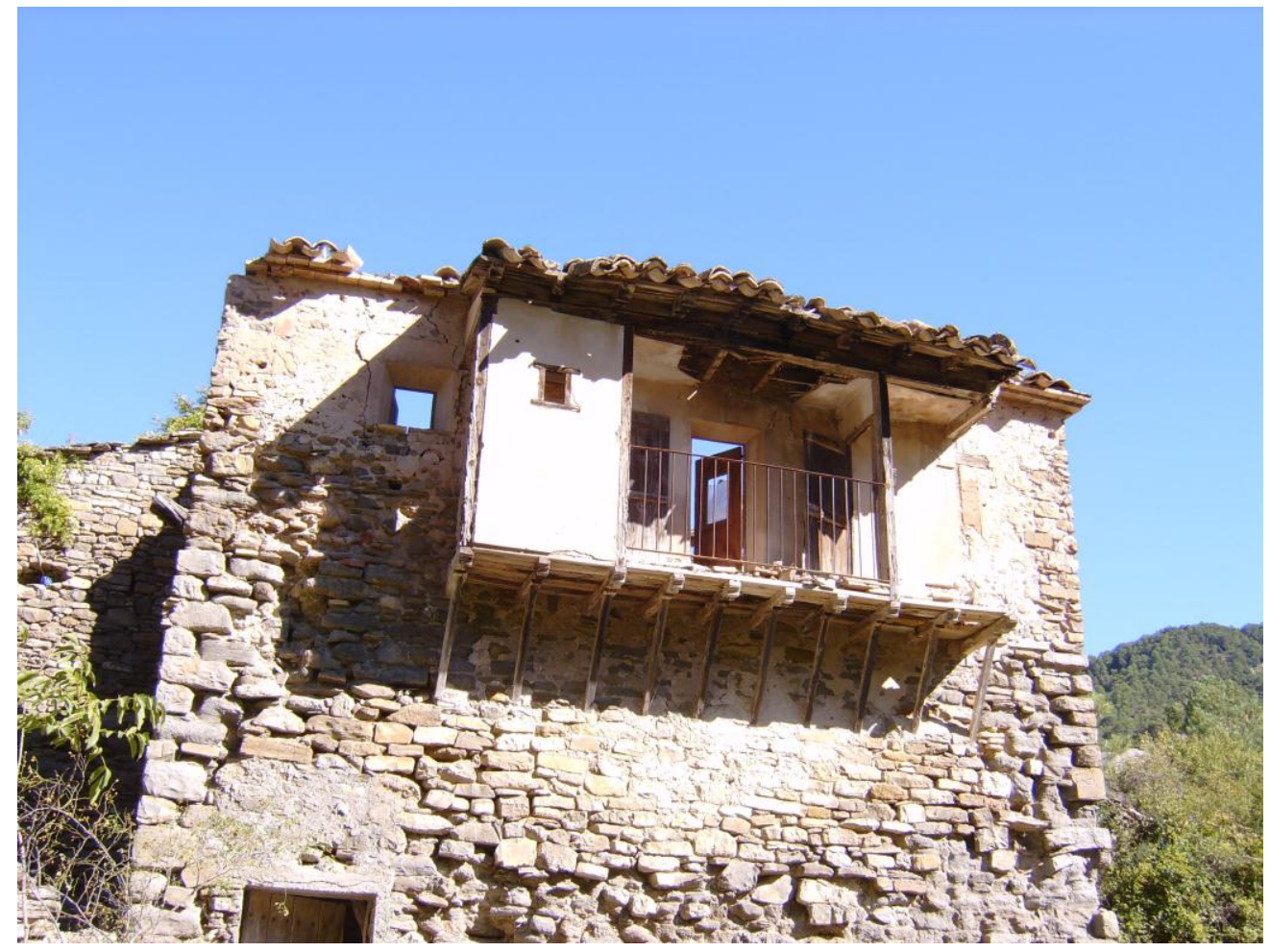

La Casa de las Salinas

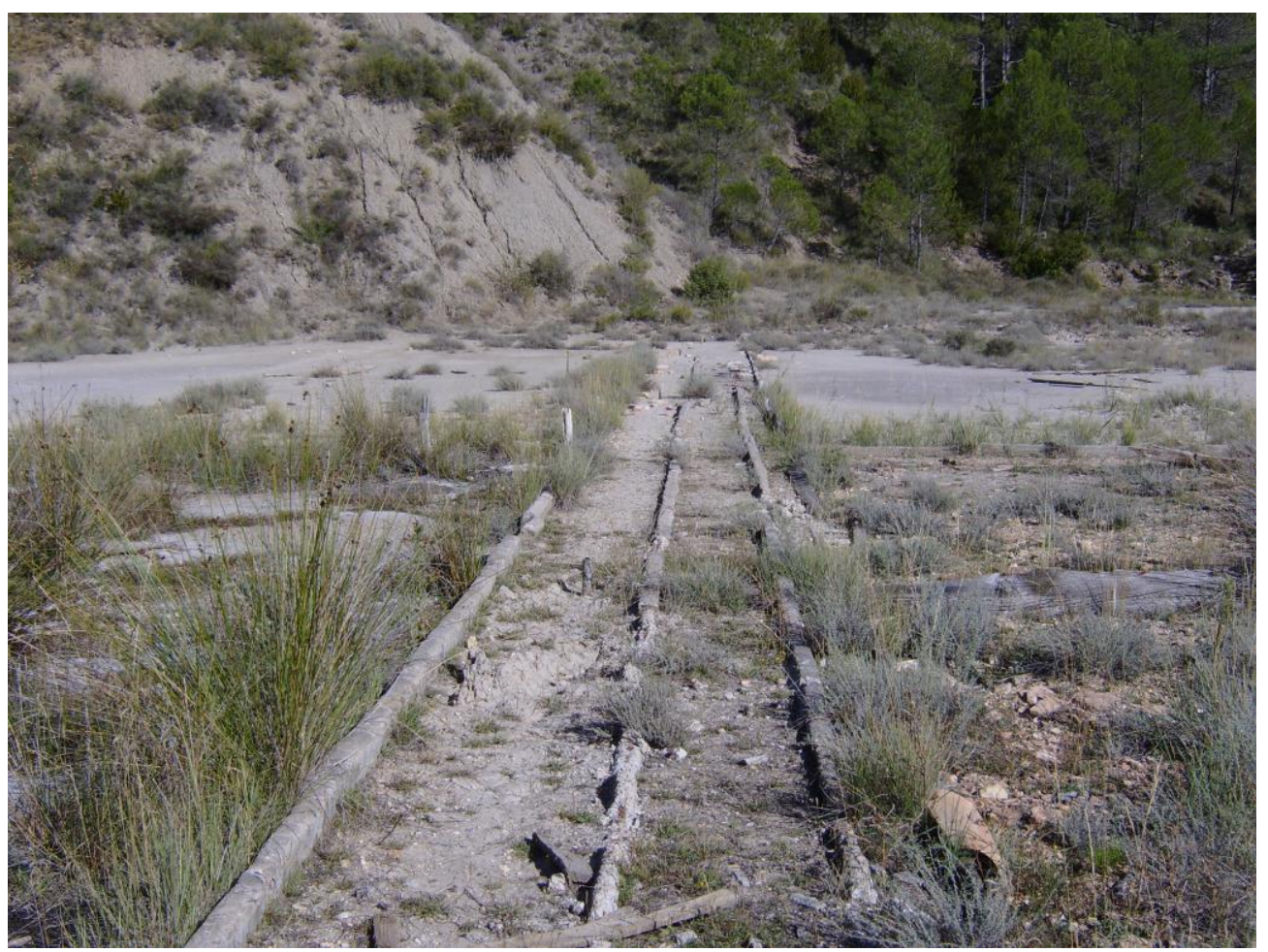

Las conducciones de madera en las eras 
Sin duda alguna, este conjunto patrimonial, es uno de los más importantes de toda la comarca del Sobrarbe, sin ningún lugar a dudas, siendo necesaria una acción decidida a evitar su pérdida y degeneración

\section{EN ESTE LUGAR FINALIZA EL ITINERARIO}

\section{BIBLIOGRAFÍA}

CALVO, M. et altri (1988). - Minerales de Aragón, Colección Temas Geológicos, 207 Pág. Zaragoza

GOBIERNO DE ARAGÓN (2001).- Puntos de Interés Geológico de Aragón. Consejería de Medio Ambiente del Gobierno de Aragón. Zaragoza

IGME (1972).- Mapa Geológico de España a escala 1:200.000 (Síntesis de la cartografía existente). Hoja y Memoria nº 23 (Huesca). Inst. Geol. Min. España

IGME (1973).- Mapa Metalogenético de España a escala 1:200.000. Hoja y Memoria no. 23 (Huesca). Inst. Geol. Min. España

IGME (1975).- Mapa de Rocas Industriales de España a escala 1:200.000. Hoja y Memoria no 23 (Huesca). Inst. Geol. Min. España

MAESTRE, A. (1845).- Descripción geognóstica del Distrito Minero de Cataluña y Aragón. Anales de Minas, t. III. Madrid

MATA - PERELLÓ, J.; (1987).- Introducción al conocimiento de las mineralizaciones aragonesas. Mineralogistes de Catalunya, t.III, pp. 258-265. Barcelona

MATA - PERELLÓ, J.M. (1992).- Inventario Mineralógico de la comarca del Sobrarbe. Rodeno, 13. 42 Pág. Manresa

MATA - PERELLÓ, J.M. y SANZ-BALAGUË, J. (1992).- Guía de Identificación de Minerales, adaptada fundamentalmente a la Península Ibérica. Edic. Parcir, 243 pag. Manresa

PRAMES (2005).- Sobrarbe. Colección RUTASCAL por Aragón. Prames, Gobierno de Aragón. 119 pag. Zaragoza. 